\title{
A docência e a violência estudantil no contexto atual
}

- Naime Pigatto*

\section{Resumo}

Este artigo apresenta uma reflexão sobre as ações docentes diante da violência estudantil. Para tal, apresentamos referencial teórico sobre o papel dos professores na resolução dos conflitos que ocorrem entre os estudantes, bem como buscamos caracterizar a violência na escola. 0 estudo exploratório teve por base os pressupostos da abordagem qualitativa e caracterizou-se por uma pesquisa bibliográfica e de campo. A partir dos dados coletados foi possivel identificar que as ações docentes em prol da resolução pacífica da violência estudantil requerem o apoio do Estado e de toda a sociedade. A afetividade, o diálogo reflexivo e a flexibilidade do planejamento pedagógico também perpassam uma docência que busca o aprendizado dos educandos, alicerçado nos princípios de uma educação para a paz. Palavras-chave: Docência. Violência na escola. Alunos.

\section{The teaching profession and the student violence in the present context Abstract}

This article presents a reflection about the teachers' actions towards the student violence. We present a theoretical study about the role of the teachers concerning to the resolution of the conflicts that occur among the students, as we also try to characterize the violence in the school. The study was based on the qualitative approach and it was characterized for being a bibliographical research as well as a field research. By the collected data we could identify that the teachers' actions to solve the student violence in a pacific way require the support of the State and also the support of the whole society. The affectiveness, the reflexive dialogue and the flexibility of the pedagogical planning constitute a kind of

\footnotetext{
* Mestre em Educação pelaPontifícia Universidade Católica do Rio Grande do Sul (PUCRS); Especialista em Direito da Criança e do Adolescente; Psicopedagoga; Pedagoga; Docente da Universidade Luterana do Brasil (ULBRA), Carazinho, RS. E-mail: naimepigatto@terra.com.br
} 
teaching that seeks the students' learning based on the principles of an education for peace.

Keywords: Teaching profession. Violence at school. Students.

\section{La docencia y la violencia estundatil en el contexto actual Resumen}

Este artículo presenta una reflexión acerca de las acciones de los profesores ante la violencia estudiantil. Con este fin, se presenta el marco teórico sobre el papel de los docentes en la solución de los conflictos que ocurren entre los alumnos, y trata de caracterizar la violencia en la escuela. El estudio exploratorio se basa en la hipótesis de la aproximación cualitativa y una búsqueda bibliográfica y de campo. A partir de los datos recogidos, fue posible identificar que las acciones de los profesores a la solución pacífica para la violencia de los estudiantes requieren el apoyo del Estado y de la sociedad en su conjunto. El afecto, el diálogo reflexivo y la flexibilidad de la planificación del proceso educativo permean el trabajo del profesor, que busca el aprendizaje de los alumnos, basada en los principios de la educación para la paz.

Palabras clave: Docencia. Violencia en la escuela. Alumnos.

\section{Introdução}

A escola, como agência socializadora e mediadora dos conhecimentos socialmente adquiridos pela sociedade, se vem deparando com o fenômeno da violência estudantil, através de cenas de agressividade entre alunos, tráfico de drogas, furtos, indisciplina, depredações e desrespeito com os profissionais que nela atuam.

Essa realidade tem sido motivo de preocupação para muitos professores que, na maioria das vezes, se sentem despreparados, inseguros e intimidados para lidar com essa problemática existente no lado de dentro dos muros escolares.

Mesmo diante desses sentimentos, a preocupação com a segurança e a tranquilidade dos alunos, na escola, bem como a discussão sobre direitos e deveres, cidadania e não violência, é trabalho cotidiano de muitos professores de escolas públicas e particulares no Brasil. Esse fato revela que o comportamento estudantil na atualidade quer, mais do que nunca, uma política educacional de qualidade, atendendo verdadeiramente às demandas da escola atual, bem como o envolvimento da sociedade civil no contexto educacional. Entendemos que a violência na escola não pode ser trabalhada como um fenômeno isolado, já que é parte integrante de um processo mais amplo que diz respeito a toda uma conjuntura social. 
A docência, diante dessa realidade, é desafiada a desenvolver atividades didático-pedagógicas embasadas numa metodologia que respeite a doutrina da proteção integral à infância e à adolescência preconizada no Estatuto da Criança e do Adolescente, bem como promover a reflexão/ação dos educandos a partir dos acontecimentos presentes em seu cotidiano, de modo que os conflitos existentes possam ser solucionados de forma pacífica.

Considerando esse contexto, este artigo tem como objetivo geral refletir sobre as ações docentes diante da violência estudantil.

Inicialmente, abordaremos a docência na resolução de conflitos e a violência na escola. Em seguida, apresentaremos a metodologia do estudo realizado, bem como aspectos relevantes dos dados coletados numa escola pública do interior do Rio Grande do Sul. É importante esclarecer que as reflexões aqui apresentadas não esgotam o assunto.

\section{Fundamentação teórica}

A escola, como instituição educadora, vem sentindo os reflexos de uma geração infanto-juvenil que está crescendo influenciada por imagens de comportamento violento, agressivo, criminoso e instável do mundo atual.

0 fazer docente na contemporaneidade exige olhar atento para as demandas da sociedade. Nesse sentido, é impar a efetivação de atividades alicerçadas em vivências cidadãs, de respeito às regras de convivência e à resolução pacífica dos conflitos.

Conforme Delors (2003, p. 89), "[...] à educação cabe fornecer, de algum modo, os mapas de um mundo complexo e constantemente agitado e, ao mesmo tempo, a bússola que permite navegar através dele". Em relação a isso, os professores precisam organizar seu planejamento cotidiano embasados nos pilares da educação, caracterizados no aprender a ser, aprender a conhecer, aprender a conviver e aprender a fazer. Nesse sentido, Barbosa $(2002$, p. 30) acrescenta que "[...] ensinar e aprender precisam estar encharcados de conhecimento, de humanização, de ação e de interação diferentes daqueles exigidos em outros momentos históricos".

0 aprender a conhecer deverá balizar-se a partir do sentido crítico e do discernimento diante das cenas de violência e de conflitos identificados; o aprender a fazer promoverá o estabelecimento de relações no processo de saber gerir e propor a resolução de conflitos; o aprender a ser, consistir-se-á no desenvolvimento de atividades que proporcionem a construção de comportamentos atentos para a espiritualidade, para a sensibilidade e o discernimento diante de situações cotidianas; o aprender a viver juntos deverá despertar no educando a reflexão sobre a existência de semelhanças e de diferenças entre os seres humanos, bem como o entendimento do outro e o respeito às suas individualidades. Dentro dessa perspectiva, é urgente uma 
escola que contemple ações educativas promotoras de aprendizagens conjuntas e significativas, em os alunos realmente possam trabalhar em grupos, inserir-se no meio em que vivem e socializarem os conhecimentos construidos coletivamente.

É nesse contexto que Nóvoa (2001) chama a atenção do professor. Em seu entendimento, o docente é chamado a rever o seu papel, atualizar-se permanentemente a fim de desenvolver práticas pedagógicas efetivas e promotoras de uma educação que promova a vida, procurando desenvolver no educando o pensar e 0 agir diante das diferentes situações que se apresentam em seu cotidiano.

Para Masetto (1997, p. 46), o professor deve compreender que:

No processo ensinoaprendizagem, o aluno é o sujeito e construtor do processo. A aprendizagem envolve sempre alguma mudança de comportamento ou de situação. Isto é, só acontece na pessoa do aprendiz. Ela é estritamente pessoal. Dessa forma, ou o aluno aprende, ou ninguém aprenderá por ele.

Entendemos que os professores, diante de situações de conflitos entre os educandos, necessitam manter a calma a fim de evitar a impulsividade. Precisam estar atentos para compreender e conviver com os alunos deste novo tempo: o do século XXI. Através de uma relação afetiva e amigável em que prevaleçam o respeito, a confiança mútua, o diálogo e a sinceridade é possivel desenvolver situações de ensino-aprendizagem significativas e próximas da vida dos estudantes.

Libâneo, Oliveira e Toschi (2003, p. 310) enfatizam que hoje o exercício profissional docente compreende ao menos três atribuições: a docência, a atuação na organização e na gestão da escola e a produção de conhecimentos pedagógicos. Diante disso, entendemos que o papel do professor não é restrito à sala de aula. Sua participação junto à equipe escolar para discutir, apontar sugestões e expor dúvidas é imprescindivel. Afinal, ele é considerado também o porta-voz dos futuros membros da sociedade. Nesse sentido, é possivel perceber que o desenvolvimento profissional do professor não depende apenas dele mesmo, mas também da instituição em que atua e, sobretudo, do compromisso do Estado em dar condições efetivas para que ele possa concretizar projetos.

Para Imbernón (2005, p. 20) o docente, ao desempenhar sua atividade, participa da emancipação das pessoas. Assim:

0 professor ou a professora não deveria ser um técnico que desenvolve ou implementa inovações prescritas, mas deveria converter-se em um profissional que deve participar ativa e criticamente no verdadeiro processo de inovação e mudança, a partir de e em seu próprio contexto, em um processo dinâmico e flexível. 
Esse processo dinâmico e flexível depende da organização curricular da escola que tem a finalidade de tornar reais as ideias, ou seja, transforma os princípios educacionais em atividades. Por isso, o currículo não pode ser visto apenas como uma relação de conteúdos previamente estabelecidos, pois ele é antes de qualquer coisa, toda e qualquer atividade ou experiência trabalhada e integrada ao processo de ensino e aprendizagem.

No processo de ensino-aprendizagem, Tuvilla Rayo (2004, p. 108-109) explica que a vida, tanto na escola como na comunidade, necessita de colaboração, cooperação e normas para que as necessidades humanas básicas sejam atendidas, bem como os conflitos que se produzem sejam resolvidos:

[...] Reconhecer e assimilar aqueles valores morais que podem ser entendidos como universalmente desejáveis é um dos objetivos da educação. [...] é importante que os estudantes considerem detalhadamente os valores, a dinâmica e os resultados que acompanham o uso tanto da violência direta como da violência estrutural imersa no seio de nossas sociedades. E sobretudo, compreender e tomar consciência de que a violência não é a única, nem a mais eficaz, das maneiras de enfrentar os conflitos, embora esteja presente como tal em nossa sociedade e seja contínuo slogan nos meios de comunicação.

0 referido autor (TUVILLA RAYO, 2004, p. 110) entende que os professores são elementos fundamentais numa proposta educativa que contemple os valores e os direitos humanos. Mostra-nos que os Direitos Humanos devem ser entendidos como os "[...] elementos básicos de uma cidadania que exige uma atitude de respeito em relação à dignidade da pessoa em sua dimensão individual e coletiva" assim como, implica reconhecer as peculiaridades na maneira de compreender o mundo.

Tuvilla Rayo (2004, p. 110) também evoca a importância da Educação para a Paz, pois esta, no seu entendimento, busca contribuir para a formação de sujeitos que possam promover a vigência dos Direitos Humanos a fim de favorecer a superação de obstáculos que impedem a promoção da vida. Para ele, a Educação para a Paz precisa ser compreendida e trabalhada de modo que seja uma "[...] resposta à problemática mundial a partir da ótica dos direitos humanos", alicerçada na cooperação, no diálogo e no intercâmbio entre indivíduos e sociedades.

Dessa forma, a prática pedagógica de uma Educação para a Paz implicaria permitir aos educandos escrever, falar e:

[...] pensar o mundo em uma linguagem com significados múltiplos, o que implica permitir-lhes o acesso ao conhecimento, o desenvolvimento de suas capacidades e oportunidades para discordar criticamente sobre a forma de como é governado o mundo (TUVILLA RAYO, 2004, p. 111). 
Para isso, faz-se necessário que os professores trabalhem na perspectiva da cultura da não violência e façam uma reflexão sobre o modo como o currículo da escola está organizado.

A Educação para a Paz, de acordo com Tuvilla Rayo (2004, p. 123), exige um trabalho de sensibilização diante das situações de agressão ou de colaboração que se manifestam ora nas instituições escolares, ora nas comunidades: "Começa por uma conscientização do que se passa, para depois desenvolver aquelas habilidades sociais que permitam aos alunos viver em harmonia consigo mesmo, com os demais, no seio de uma sociedade e com o meio natural". 0 autor (TUVILLA RAYO, 2004) chama a atenção, ainda, para os conteúdos básicos que derivam dos Direitos Humanos: o direito ao desenvolvimento, o direito à paz, o direito à diferença, 0 direito ao patrimônio comum da humanidade e o direito a um ambiente saudável e ecologicamente equilibrado.

Logo, a educação escolar na contemporaneidade deverá levar em conta, segundo Imbernón (2000, p. 93), diferentes habilidades além da leitura e da escrita, como, por exemplo, o discurso narrativo, a consciência crítica, o trabalho conjunto, o debate e o diálogo. Esses:

[...] permitirão a construção de um pensamento capaz de selecionar informações relevantes; de conhecer e preservar-se da influência dos meios de comunicação e de outras fontes de poder; de analisar as desigualdades entre os que produzem informação e os que a consomem; de tomar decisões; de fazer relações [...].

Conforme Vasconcellos (2001, p. 33), um dos grandes problemas da escola hoje é a inexistência de uma proposta político-pedagógica assumida socialmente pela sua comunidade escolar: "Há a afirmação genérica de 'formação da cidadania', porém, não se define com exatidão o que isso quer dizer".

Vasconcellos (2001, p. 37) também chama a atenção para o papel coletivo da sociedade na promoção do desenvolvimento humano: "[...] a educação corresponde a este amplo esforço, pessoal e coletivo, de constituir o ser humano na sua plenitude [...]. É evidente que a tarefa de humanização não cabe a uma instância em particular, mas a toda sociedade".

0 mesmo autor (VASCONCELLOS, 2001, p. 38) compreende a educação escolar como um "[...] sistemático e intencional processo de interação com a realidade", em virtude das relações humanas que ali existem baseadas no conhecimento e em como a coletividade está organizada. Afirma que sua finalidade é "[...] colaborar na formação do educando na sua totalidade - consciência, caráter, cidadania -, tendo como mediação fundamental o conhecimento que possibilite a emancipação humana". 
Mostra, ainda, que a educação escolar tem a tarefa de "[...] procurar motivar, de provocar, despertar o desejo, bem como buscar a interação dos desejos (professores e alunos) visando à formação e à construção de seus agentes". Nesse sentido, para acontecer o "encontro educativo", as pessoas precisam estar em busca de algo, ter objetivos e que "[...] reciprocamente essas finalidades possam, de alguma forma, interagir, ter algo em comum" (VASCONCELLOS, 2001, p. 39).

É pensando no encontro educativo e na formação do humano existente na escola, que passaremos, neste momento, a refletir sobre a violência na escola e as implicações dessa problemática que muitas vezes afasta educadores e educandos.

A escola vem na atualidade se deparando com o fenômeno da violência no seu interior, transformando-se, muitas vezes, num palco de acerto de contas de gangues rivais, da prática do bullying ${ }^{1}$, do vandalismo ao seu patrimônio, bem como, da agressão verbal e física dos alunos a seus professores. Tem-se deparado, principalmente enquanto instituição pública, com uma realidade cultural, econômica, social e política de fragilidades, sentindo-se limitada na formação dos diferentes perfis de alunos, diante da precariedade em que se encontram os seus recursos estruturais, financeiros e qualitativos disponiveis.

Gimeno Sacristán (2000) destaca que, nas relações sociais, a educação escolar é fator de primeira ordem na formação do cidadão apesar de assemelhar-nos a alguns e distanciar-nos socialmente de outros.

Acrescentando, Schilling (2004) afirma que a escola brasileira tem sido estudada como o lugar das grandes desigualdades, como também, uma instituição promotora da superação destas quando procura formar e potencializar os talentos de cada cidadão buscando construir uma democracia justa e duradoura.

Imbernón (2000, p. 86-87) apresenta uma nova escola diante de uma sociedade plural no que se refere às condições de trabalho, família, cidadania e dignidade humana. Para ele, a educação escolar da contemporaneidade deve superar a visão tradicional histórica que socializava seus educandos nos "[...] valores hegemônicos e nos conhecimentos apropriados do ponto de vista da cultura dominante". Considera ainda que insistir nesse paradigma é rumar para o fracasso e para a obsolescência. Afirma, ainda, que a sociedade da informação, na qual vivemos, "[...] requer uma educação intercultural quanto aos conhecimentos e aos valores, assim como a vontade de corrigir a desigualdade das situações e das oportunidades".

\footnotetext{
"Bullying é um termo inglês utilizado para descrever atos de violência física ou psicológica, intencionais e repetidos, praticados por um indivíduo (bully ou "valentão") ou grupo de indivíduos com o objetivo de intimidar ou agredir outro indivíduo (ou grupo de indivíduos) incapaz(es) de se defender.” (WIKIPEDIA, 2010).
} 
A criminalidade, o aumento da drogadição e do tráfico, a falta de ética e do respeito às regras influenciam a qualidade do trabalho docente e a aprendizagem do educando. Essa realidade mostra que a violência deve ser olhada não somente pelo aspecto físico, mas como tudo aquilo que desrespeita, constrange e humilha. Que é impetuoso, arromba a vida e que é, portanto, contrária à justiça.

Segundo Nascimento (2006), a violência deve ser entendida a partir de fenômenos estruturais como a crise econômica e a miséria, bem como o complexo de mediações culturais e materiais que se expressam na quebra dos laços de solidariedade e na crise das relações sociais tradicionais. Essa idéia é complementada por Schilling $(2004$, p. 38) quando acrescenta que a violência precisa ser compreendida levando em conta os seus aspectos físicos e morais, pois:

[...] a violência é um ato de brutalidade [...] e caracteriza relações intersubjetivas e sociais definidas pela opressão e intimidação, pelo medo e pelo terror [...] se opõe à ética porque trata seres racionais e sensiveis, dotados de linguagem e de liberdade, como se fossem coisas [...].

O fenômeno da violência, na conjuntura atual, também pode ser explicado a partir da análise que Bauman $(1998,2001)$ faz da sociedade moderna. Segundo o autor (BAUMAN, 2004, p. 129), a sociedade pode ser caracterizada como líquida, pois a liquidez traz consigo uma "[...] misteriosa fragilidade dos laços humanos - um amor líquido". Esse fato, segundo o autor, ocasiona insegurança, que é inspirada e estimulada por desejos conflitantes de estreitar os laços e, ao mesmo tempo, mantê-los frouxo.

Os problemas da violência na instituição escolar causam muitos transtornos em seu interim, pois a escola, por si só, "[...] inscreve-se na ordem da linguagem e da troca simbólica e não na da força física" (CHARLOT, 2002, p. 436). 0 autor considera ainda que a agressividade e os conflitos nesse espaço deveriam ser regulados "[...] pela palavra e não pela violência - ficando bem entendido que a violência será bem mais provável, na medida em que a palavra se tornar impossivel".

Os delitos contra objetos, a quebra de portas e vidraças, a depredação de banheiros, o descuido com o asseio das áreas coletivas, as posturas ameaçadoras e sexistas de determinados alunos estão muito presentes no cotidiano escolar. Esses fatos denotam descaso e atitudes insensiveis para com o patrimônio da instituição de ensino e para com os direitos do cidadão, neste caso, os docentes, os funcionários e os próprios colegas.

A respeito disso, Nascimento $(2006$, p. 6) afirma que entram em cena na escola atual as relações de força, a construção e a autorreprodução de uma cultura da violência, pois: 
0 intensivo processo de urbanização, o desenraizamento cultural, afetivo e religioso, a acelerada industrialização, a concentração de renda, o desemprego, os altos índices de consumo e a crise na ética [...] têm contribuido para a construção de uma sociedade apática em relação aos problemas sociais [...].

Nessa passagem do autor, nos deparamos com a idéia de que a violência passou a ser vista como corriqueira e habitual em algumas instituições, levando os educadores a defini-la como decorrente de situações complexas e impossíveis de mudanças.

Charlot (2002), ao retratar a violência na escola, também faz distinção entre a violência da escola e a violência à escola. 0 autor caracteriza violência $d a$ escola como a violência institucional, simbólica, através das relações de poder estabelecidas pelos professores a seus alunos. A violência à escola é aquela que visa à instituição e àqueles que a representam. A violência na escola, objeto de nosso olhar, é aquela que se produz dentro do espaço escolar.

Abramovay (2002b) caracteriza a violência na escola a partir de três dimensões sócio-organizacionais: a estrutura deficiente do ambiente escolar que gera dificuldades à equipe diretiva, a violência organizada fora dos muros escolares e que se manifesta através da penetração de gangues e tráfico de drogas, e também pela própria característica histórica de cada escola que se mostra violenta, ou então, que passa por situações de violência. A referida autora (ABRAMOVAY, 2002a, p. 70) considera, ainda, a violência escolar como "[...] uma transgressão da ordem e das regras da vida em sociedade" como, por exemplo, "[...] violência contra os bens individuais (roubo e extorsão), contra a propriedade coletiva (vandalismo), as violências verbais ou morais contra alunos, funcionários e professores e as violências físicas".

A escola atual já não pode mais ser considerada como um lugar seguro, onde os docentes, discentes e funcionários estão protegidos dos perigos de uma sociedade violenta, de frágeis laços humanos e de alunos que atormentam e acabam gerando confusões. Esses fatos fazem com que no ambiente educativo seja criado um clima de insegurança e desconforto:

Tudo se passa como se a violência na escola estivesse convertendo-se em um fenômeno estrutural e não mais, acidental e como se, depois de instalada nas escolas de bairros problemáticos, ela se estende hoje a outros estabelecimentos (CHARLOT, 2002, p. 434).

Diante do exposto, é importante refletir sobre qual é o sentido da educação escolar diante de toda essa realidade que se apresenta no contexto escolar? A complexidade dos acontecimentos mostra que é urgente à escola repensar o seu planejamento escolar e a maneira como atua diante das dificuldades com que se depara. 


\section{Metodologia do estudo}

0 presente estudo é um recorte de nossa monografia apresentada ao curso de especialização em Direito da Criança e do Adolescente, da Fundação Escola Superior do Ministério Público do Rio Grande do Sul. Para a investigação utilizamos a abordagem qualitativa, pois ela se fundamenta em descrições detalhadas de situações, sendo importante na identificação conceitual de valores encontrados entre os sujeitos pesquisados e dificeis de quantificar, tais como: sentimentos, atitudes individuais, crenças, etc. (BOGDAN; BIKLEN, 2003).

A população do estudo foram os professores de uma escola de tempo integral pública, cujos alunos são oriundos de uma comunidade carente do município de Carazinho, interior do Rio Grande do Sul. Para amostragem, foram escolhidas as professoras atuantes nos Anos Iniciais do Ensino Fundamental, a coordenadora pedagógica e a vice-diretora. A escolha esteve relacionada à realidade da referida escola, uma vez que os professores dos Anos Iniciais estão, cada vez mais, deparando-se com estudantes que não respeitam regras e tumultuam o andamento das atividades cotidianas.

A pesquisa exploratória teve os dados coletados através do uso da entrevista semiestruturada, uma vez que ela é considerada um dos instrumentos básicos na perspectiva da pesquisa qualitativa. Os nomes das professoras entrevistadas, bem como da referida instituição foram omitidos. Os dados coletados foram analisados a partir das orientações da Análise de Conteúdo. Inicialmente foram trabalhados através de uma descrição cuidadosa e pormenorizada das questões e, em seguida, submetidos à compreensão e à interpretação do fenômeno, tomando por base a fundamentação teórica.

Após a análise descritiva, apresentamos momentos significativos que retratam como as docentes investigadas percebem e atuam diante da violência estudantil.

\section{Apresentação e discussão dos resultados}

Uma das professoras participantes, quando questionadas sobre seu comprometimento profissional diante dos alunos, relatou seu medo em trabalhar numa comunidade carente e com graves problemas de relacionamentos socioafetivos que acabam se repercutindo na escola. Afirma ainda:

Apesar de toda dificuldade, nós lutamos e vencemos. Mas, sempre no início de cada ano, apesar de toda minha caminhada, me dá um 'medão', daqueles bem loucos! E olha que eu sou bem tranquila! Cada vez tu tens que se dedicar mais, ter mais responsabilidades, porque o aluno, um é diferente do outro a cada ano que passa (P1). 
0 relato da docente mostra o reconhecimento do perfil dos alunos e a preocupação com a realização de um bom trabalho diante das dificuldades que permeiam a organização e o funcionamento da escola.

Em relação à resolução pacífica dos conflitos que se estabelecem no interior das salas de aula, uma das professoras afirmou a existência de um trabalho voltado à pedagogia do afeto e da atenção, pois, segundo ela, favorece um ambiente menos hostil para o processo ensino-aprendizagem:

0 que a gente percebe que é bem saliente é o toque. Eu sou uma pessoa assim, que chega e abraça o aluno. Às vezes, a gente chega só para passar o braço, para abraçar. A criança já se vira armada achando que é uma agressão. Então, de repente, por isso a agressividade deles é tão aflorada (P2).

Conforme identificamos, o carinho, a afetividade e a paciência docente são etapas fundamentais no processo de inserção dos alunos no exercício da cidadania. Essas ações revelam a existência de um currículo oculto no âmbito das salas de aula das professoras investigadas atento às relações humanas, a partir da maneira como são estabelecidas as relações de amizades e a confiança entre alunos e professores.

Enquanto processo dinâmico e sujeito às inúmeras influências, o currículo descreve a concretização das funções da própria escola e a forma particular de enfocálas num determinado momento histórico e social. 0 Parecer CNE/CEB n ${ }^{\circ} 4$ (CONSELHO NACIONAL DE EDUCAÇÃO, 1998) traz definições importantes que devem ser observadas no tocante ao conceito de currículo:

[...] atualmente este conceito envolve outros três, quais sejam: currículo formal (planos e propostas pedagógicas), currículo em ação (aquilo que efetivamente acontece nas salas de aula e nas escolas) e currículo oculto (o não dito, aquilo que tanto alunos, quanto professores trazem, carregado de sentidos próprios criando as formas de relacionamento, poder e convivência nas salas de aula).

Seguidamente, o tema violência na escola faz parte das reuniões de professores da instituição, conforme as professoras o relataram. Há a preocupação com o cumprimento do currículo oficial, que fica comprometido diante dos vários problemas que se apresentam diariamente em sala de aula, evidenciando a importância de a família fazer a sua parte e as críticas que os professores de escolas públicas recebem:

Não é fácil! Às vezes tu perdes o tempo que tu tinhas que estar dando aula para fazer a função da família. Ai tu tens que parar com a instrução. Ai se fala que na escola pública falta qualidade. 0 professor da escola pública tem que se ocupar em ensinar até mesmo como se senta, como as 
pessoas devem se comportar na mesa, como pegar um garfo, mastigar bem os alimentos... Tudo isso a gente tem que ensinar. E daí, o nosso programa mesmo, como é que fica? Dai é fácil as pessoas criticarem [...].

Em relação a esse relato, é possível identificar que a organização curricular da escola e as ações docentes não estejam alinhadas, pois o ensinar a ser e conviver devem estar integrados com o ensinar a conhecer os conteúdos formais estabelecidos pela instituição. Veiga (2001, p. 27) afirma que o currículo não é um "instrumento neutro", pois revela a existência de uma ideologia que mascara fragilidades:

0 currículo passa ideologia, e a escola precisa identificar e desvelar os componentes ideológicos do conhecimento escolar que a classe dominante utiliza para a manutenção de privilégios. A determinação do conhecimento escolar, portanto, implica uma análise interpretativa e crítica, tanto da cultura dominante, quanto da cultura popular. 0 currículo expressa uma cultura.

Entendemos que o currículo não pode ser separado do contexto social e que as escolas devem buscar novas formas de organização curricular, tentando superar sua organização fragmentada e cumpridora de prazos previamente estabelecidos.

A organização globalizada dos conteúdos é uma proposta que poderia ser pensada frente às atuais circunstâncias de agressividade e problemas de relacionamento. A Lei de Diretrizes e Bases da Educação Nacional, Lei n 9.394 (BRASIL, 1996), deixa bem claro no seu Artigo 12, inciso I, que a escola, ao elaborar e executar a sua proposta pedagógica, deve levar em consideração o meio no qual está inserida. Discutir e propor projetos junto aos alunos, que envolvam a criminalidade, a drogadição, as agressões físicas e verbais são ações pontuais de um currículo comprometido com a formação humana e cidadã de seus educandos.

Em relação ao tema família, escola e sociedade, identificamos que o reduzido tempo que o estudante permanece no ambiente escolar é ineficiente diante de uma comunidade que também ensina lições que vão de encontro àquelas apregoadas pela escola, conforme relatou uma das professoras:

0 tempo está contra nosso trabalho. Porque aqui você ensina uma coisa, aí eles vão pra casa. Daí no outro dia parece que eles esquecem tudo o que você falou porque alguém lá fora falou coisa diferente. Nós estamos lutando contra a comunidade porque nós temos quatro horas de sala de aula, e eles têm vinte horas fora, aprendendo as coisas que vem de encontro ao que a escola aplica. A comunidade prega os seus valores e nós estamos aqui pregando outras coisas. Eles falam outra língua. E nós não falamos a mesma linguagem (P3). 
Ficou identificado também que a instituição escolar precisa urgentemente encontrar alternativas para buscar aproximar-se da comunidade em que está inserida.

Sabemos da importância que a escola tem na vida da criança e que o tempo em que ela está nesse ambiente é fundamental. Por isso, as atividades devem ser cuidadosamente preparadas. 0 que podemos identificar é que a comunidade e a família estão distantes das ações docentes desenvolvidas, ficando o ensino-aprendizagem prejudicado, conforme o relato que segue: "A participação dos pais no acompanhamento dos estudos dos filhos é precária, quase nula. Tem pai que chega aqui na escola e não sabe nem a série dos filhos".

Masetto (1997) refere que o espaço escolar deve oferecer uma forte interação com a realidade externa do aluno, possibilitando-Ihe a identificação de um ponto de referência. 0 autor também afirma que o espaço escolar disponibiliza um ótimo exercício para a convivência em sociedade, pois cada um tem seu modo de viver, brincar, estudar e de se relacionar. Para ele, a sala de aula é um espaço de relações e deve ser vista como um lugar privilegiado para a aprendizagem e um local de convivência social.

Cubero e Moreno (1995, p. 254) destacam que a escola é a instituição mais importante depois da família. Diante disso, fica ressaltada a sua importância perante o processo de desenvolvimento de seus educandos.

A escola não só intervém na transmissão do saber científico organizado culturalmente, como influi em todos os aspectos relativos aos processos de socialização e individuação da criança, como são o desenvolvimento das relações afetivas, a habilidade de participar em situações sociais, a aquisição de destrezas relacionadas com a competência comunicativa, o desenvolvimento do papel sexual, das condutas pró-sociais e da própria identidade pessoal [autoconceito, auto-estima, autonomia].

Com base nisso, é importante refletir sobre o papel e responsabilidade da escola e dos profissionais que nela atuam. Barros (1997) refere que a escola, mesmo desempenhando um papel menor na personalidade do seu educando em relação à família, não pode desconsiderá-lo, pois é nela que ele vai aprender e internalizar muitos dos valores e conceitos de que precisará para se inserir e viver em sociedade.

Em relação ao tema equilíbrio e ordem, abordado durante a entrevista, percebemos a existência do zelo pelo cumprimento de regras por parte dos discentes em virtude da constante presença de furtos, socos, pontapés, gritarias, empurrões, xingamentos e depredação de banheiros e espaços de circulação. 
A professora P5 ilustra a necessidade do trabalho constante com as regras quando falou sobre a dificuldade de trabalhar em decorrência da falta de limites de seus alunos: "Uma das principais dificuldades que eu encontro para manter a paz na sala é o limite. Até você conseguir fazer com que eles entendam que têm regras vai longe [...]".

Em relação às cenas de violência dirigidas aos professores, identificamos o furto de talão de cheques e xingamentos como agressões implícitas e explícitas. Nos dois relatos a seguir ficam identificados os sentimentos de constrangimento e insegurança docentes:

Eu acredito que a violência na nossa escola não é só quando o aluno bate ou dá o soco em outro colega. A agressão verbal é uma linguagem pesada. E da agressão verbal vai para a física. Tudo começa na verbal, no olhar, nos apelidos. Assim, às vezes, tu fazes um comentário em sala de aula e vê até aquele ar de deboche sabe, de descaso! Eu já fui xingada um monte de vezes. Já tive vontade de fugir da sala de aula, de abandonar tudo! Dizer tchau, fui! (P1).

Uma vez sumiu um talão de cheques de 20 folhas que eu tinha pegado no banco e que estava dentro da minha pasta. Eu fui pro lanche porque ninguém nunca mexeu. Eu deixei a pasta na sala de aula. Quando eu fui para a parada do ônibus, cadê meu talão de cheques? Cadê meu dinheiro? Cadê minhas passagens? Aí voltei para a escola. A diretora ainda estava lá. Aí fomos à delegacia dar parte e depois eu fui ao banco pra cancelar o talão. Apareceu cheque de tudo quando era lado, até pneu compraram com estes cheques [risos]! Mas tem que levar na esportiva, na brincadeira, pois se levarmos a sério abandonamos a profissão. Muitas vezes você tem que contar até dez, parar tudo e retomar teu trabalho, porque se tu brigares com eles, a coisa vai ficar mais complicada ainda. Faço de conta que não ouvi e depois eu retomo (P2).

Diante desses acontecimentos, fica evidente a resignação que as docentes entrevistadas têm para poder contornar essas situações e dar prosseguimento ao seu trabalho, procurando ainda fazer desses momentos delicados, um aprendizado.

Furtos entre os alunos também são relatados pelas professoras. Conversas e brincadeiras com as crianças pequenas são estratégias que as docentes utilizam a fim de evitar as incidências:

Com os pequenos muitas vezes você ouve: 'Ah! Você roubou o apontador do coleguinha!'. Aí eu falo: 'Gente, de repente está misturado no material do coleguinha por isso 
que desapareceu!'. Tem casos, é lógico, que você não descobre nunca. Às vezes isso funciona: 'Bah! Será que não caiu de dentro da mochila?'. E às vezes o material aparece lá do outro lado. Como eles são pequenos não entendem [...].

Beaudoin e Taylor (2006) ressaltam que mesmo com muitas pessoas conscientes de que vivemos em uma sociedade individualista, existem outras que não percebem a implicação desses discursos no seu cotidiano. Nessas culturas, as organizações passam a estruturar-se a partir da competição, das regras, conquistas, avaliações, recompensas, punições e das hierarquias de poder. Essas nuances também aparecem na escola e podem acabar contribuindo para o desrespeito e o bullying.

Segundo Beaudoin e Taylor (2006, p. 22), bullying é a "[...] intimidação direta ou indireta cujo leque de possibilidades varia desde simples gozações em tom ofensivo até atitudes mais violentas que empreguem a força física". Essa intimidação é observada na fala de uma docente:

Aquele que agride quer o atestado de fortão, de poderoso: 'Eu sou o líder! Eu posso! Eu sou o tal, ou então eu bato em você! Se vocês não me derem tal coisa, ou então, se vocês não fizerem pra mim eu bato em vocês!'. Existem muitas ameaças. Eles ainda dizem: 'Eu sou o melhor! Eu sou o importante!'. Então isso gera medo, uma grande confusão!

Em relação ao bullying e às demais situações cotidianas de violência que prejudicam o desenvolvimento saudável dos educandos na escola, o Estatuto da Criança e do Adolescente, Lei no 8.069 (BRASIL, 1990) ao trazer à sociedade, à família e à escola a responsabilidade da proteção integral às crianças e adolescentes em virtude da sua condição peculiar de pessoa em processo de desenvolvimento, chama a atenção para as medidas de proteção, que são aplicadas tanto à infância como à juventude.

Em seu Artigo 98, o Estatuto da Criança e do Adolescente (BRASIL, 1990), estabelece medidas de proteção aplicáveis às crianças e aos adolescentes, quando seus direitos forem ameaçados ou violados, quer por ação ou omissão da sociedade ou do Estado; por falta, omissão ou abuso dos pais ou responsável; bem como em razão de sua conduta. Essas medidas têm como prerrogativa cuidar e proteger a criança e 0 adolescente.

O Artigo 101 do Estatuto (BRASIL, 1990) estabelece as medidas de proteção que são determinadas pela autoridade competente: I - encaminhamento aos pais ou responsável mediante termo de responsabilidade; II - orientação, apoio e acompanhamento temporários; III - matrícula e frequência obrigatórias em estabelecimento oficial de ensino fundamental; IV - inclusão em programa comunitário ou oficial de auxílio à família, à criança e ao adolescente; $\mathrm{V}$ - requisição de tratamento médico, 
psicológico ou psiquiátrico, em regime hospitalar ou ambulatorial; VI - inclusão em programa oficial ou comunitário de auxílio, orientação e tratamento a alcoólatras e toxicômanos; VII - abrigo em entidade; VIII - colocação em familia substituta.

Quando uma criança é envolvida com a prática infracional, a medida tratada no inciso I do Artigo 101 afirma que deve ser aplicada conjugadamente com outras medidas de proteção, por exemplo, o inciso II do mesmo artigo. Importante deixar claro que para as crianças de zero a onze anos participantes de atos infracionais, 0 Estatuto prevê, excepcionalmente, a aplicação de medidas de proteção e não medidas sócioeducativas, conforme o Artigo 105.

As medidas sócioeducativas, o Estatuto (BRASIL, 1990) prevê que são aplicáveis somente aos adolescentes entre 12 a 18 anos incompletos autores de atos infracionais. Essas medidas são diferentes das medidas de proteção, que são aplicadas aos adolescentes e às crianças. As medidas socioeducativas encontram-se no Artigo 112 do Estatuto da Criança e do Adolescente e somente poderão ser aplicadas pela autoridade competente, o Juiz da Infância e da Juventude, conforme as competências estabelecidas no Artigo 148.

Konzen (2005, p. 91), ao se reportar às medidas socioeducativas relacionadas ao adolescente infrator, clarifica a distinção entre medidas socioeducativas e penas aplicadas aos adultos:

[...] em solução à questão geral, no sentido de se saber o que é a medida socioeducativa, percebe-se a presença de uma resposta estatal de cunho aflitivo para o destinatário, ao mesmo tempo em que se pretende, com a incidência de técnicas da pedagogia, a adequada (re) inserção social e familiar do autor de ato infracional. [...] A substância é penal. A finalidade deve ser pedagógica.

0 Estatuto da Criança e Adolescente (BRASIL, 1990) também faz menção ao direito da criança a uma escola que promova atividades embasadas no pleno desenvolvimento da pessoa e no preparo para o exercício da sua cidadania, sendo que no Artigo 53, inciso I, fica estabelecida a igualdade de condições para o acesso e permanência na escola.

0 princípio da igualdade para o acesso e permanência na escola chama a atenção para os direitos e deveres dos alunos, deveres estes nem sempre discutidos e trabaIhados pelos próprios estudantes.

Diante dos dados coletados, percebemos que é fundamental a escola promover situações de ensino-aprendizagem que permitam aos seus alunos a reflexão diante 
das cenas de violência presenciadas no ambiente educativo, discutindo sobre a existência regras de convivência e o respeito à autoridade docente, bem como encontrando alternativas para superar os problemas identificados.

Ressaltamos aqui a existência do Regimento Escolar, instrumento que normatiza a organização e o funcionamento da vida da escola e estabelece, também, as noções básicas de convivência cidadã na instituição. Esse importante documento, aliado às práticas familiares no processo de ensino-aprendizagem dos limites, direitos e deveres a partir das regras de convivência, deveria ser o grande princípio norteador do educandário no processo de aplicação das regras. 0 que percebemos, não só na entrevista realizada, mas também na prática cotidiana dos professores de escolas públicas e privadas, é que esse documento nem sempre é trabalhado pelos professores em sala de aula e conhecido na sua integralidade pelos alunos e familiares.

Importante destacar também que o Estatuto da Criança e do Adolescente afirma no Artigo 18 que é dever de todos velar pela dignidade da criança e do adolescente, pondo-os a salvo de qualquer tratamento desumano, violento, aterrorizante, vexatório ou constrangedor.

Quando abordadas sobre quais seriam os instrumentos de desarme para promover um ambiente de tranquilidade e manter a paz entre os alunos e, assim, desenvolver os conteúdos de seu plano, todas foram unânimes em ressaltar a importância do diálogo, da afetividade e da constante retomada das regras: "A escola busca a valorização do ser humano, trabalhando a autoestima do aluno, valorizando, elogiando. Assim, eles percebem que estão melhorando a cada dia". Todavia, evidenciaram a necessidade de serem sempre prudentes, não vacilando nos cuidados de prevenção à violência e a homeostase do grupo: "A gente não se descuida nunca, o professor não é só dois olhos [...]".

Ainda sobre a responsabilidade da família em relação à Lei no 8.069 (BRASIL, 1990) diante do acompanhamento do desenvolvimento dos filhos, ficou evidenciado que essa instituição nem sempre corresponde ao que preceitua a referida Lei. $\mathrm{Na}$ maioria dos casos, quando os pais são chamados até a escola para reuniões e conversas particulares o que se percebe é que aqueles que mais precisam participar são os que menos comparecem.

Diante das circunstâncias descritas e dos resultados encontrados em nossa investigação, chamamos a atenção para a importância de ações docentes voltadas para a resolução pacífica dos conflitos e o respeito ao ser humano.

Segundo Tuvilla Rayo (2004, p. 124), a educação voltada para a paz "[...] enfatiza as relações que se dão com os indivíduos entre si e com a sociedade. 
Por outro lado, concilia tanto a paz interior e relacional das pessoas como favorece o equilíbrio com o meio natural, a sociedade e o mundo". Ainda segundo o mesmo autor, essa educação:

[...] deverá levar em consideração a violência desde sua perspectiva sociológica, o que leva a uma análise dos estilos de ensino, dos conteúdos curriculares e dos métodos empregados com o objetivo de garantir que os valores de cooperação e de diálogo estejam presentes tanto na organização escolar como nas relações professor/aluno (TUVILLA RAYO, 2004, p. 124).

Por fim, na temática sobre escola como um dos locais de proteção, ficou evidente mais uma vez a vontade das professoras investigadas, independente das poucas verbas e recursos que a instituição dispõe, de auxiliar nos desafios que se apresentam à sua atuação docente, auxiliando na promoção do desenvolvimento qualitativo de seus educandos a partir da promoção da sua autoestima, do incentivo às relações de afeto, do diálogo constante sobre direitos e deveres e também da sua autoavaliação enquanto profissional da educação, conforme ilustramos nas falas que seguem:

Educar pra vida pra mim é desenvolver a autoestima, analisar o que eu estou fazendo para melhorar, não só reclamar. Volta e meia nós professores temos que nos autoavaliarmos para perceber também como está o nosso comportamento. Nós muitas vezes nos queixamos dos alunos, mas não avaliamos como está o nosso trabalho (P1).

Eu penso que educar para a vida é educar para os valores. É formar um cidadão consciente de seu papel na comunidade. Um ser atuante. É educar fazendo o aluno perceber que ele é importante, que ele é um ser crítico, que ele tem que participar da comunidade. Pois queira ou não queira, ele vai ter que participar. Tem a ver com valores, o que é certo, o que é errado (P2).

Merecem ser destacados também, como desafios que se apresentam aos professores investigados, a precariedade de recursos financeiros disponibilizados à instituição pública e que comprometem a qualidade do trabalho dos profissionais da escola, o desenvolvimento de um planejamento pedagógico criativo, flexivel, crítico e globalizado, cuja ênfase esteja alicerçada no aprender a aprender (DELORS, 2003) e na educação para a paz. Realizar atividades grupais, pesquisas e teatros, bem como aquelas que promovam a aplicação e a reflexão dos conhecimentos aprendidos em sala de aula são fundamentais para o estabelecimento de novos vínculos e a convivência harmônica entre professores-alunos, alunos-alunos e alunos-funcionários. 
Envolver a família e a comunidade em eventos socioculturais e promover o debate sobre o resgate do respeito às regras, dos limites e da autoridade docente entre a comunidade escolar, também são desafios.

Outro desafio importante a ser ressaltado é que os professores saibam lidar com as situações de conflito entre os alunos, exercitando a paciência e a compreensão de que os problemas pertencem aos envolvidos e que ele deve agir sem tomar partido, promovendo diálogos constantes com os alunos sobre os direitos e deveres inerentes à convivência humana.

\section{Conclusões}

Reportando-nos aos propósitos deste artigo: refletir sobre as ações docentes diante da violência estudantil, chegamos a significativas conclusões. Dentro delas está o papel do professor, do Estado e da sociedade no trato às questões da violência estudantil, cada vez mais presentes no cenário da escola, bem como a importância da organização de um currículo flexivel, globalizado e atento às demandas de sua comunidade escolar.

Ao longo desse trabalho, buscamos ressaltar, no referencial teórico, a importância da docência na resolução dos conflitos estudantis através de uma prática que possibilite o aprendizado dos educandos através de ações embasadas no ser, no fazer, no conhecer e principalmente no conviver. Também buscamos chamar a atenção para a prática pedagógica ser voltada ao desenvolvimento de uma educação que promova a paz e que proporcione aos educandos a conscientização sobre a importância do exercício da cidadania, do diálogo e do trabalho coletivo nas atividades diárias de sala de aula.

A violência, enquanto fenômeno que atinge todas as camadas sociais, vem revelando-se cada vez mais forte no ambiente escolar. Falta de respeito à autoridade docente, depredação do patrimônio, socos e chutes, comercialização de drogas, furtos e acertos de contas de grupos rivais são algumas das situações presenciadas pelos professores investigados. Conviver e atuar nessa realidade está fazendo com que muitos profissionais que atuam na educação escolar, não somente os docentes, sintam-se acuados, desmotivados, despreparados e inclusive, com problemas de saúde.

Notamos, através da investigação feita, que assim como a escola e seu corpo docente precisam reconhecer que o seu trabalho está seriamente comprometido com o desenvolvimento humano, e consequentemente com as questões ligadas à violência nas suas mais diferentes facetas, é fundamental o Estado, através da execução qualitativa de políticas públicas, instrumentalizar os aspectos físicos e humanos na educação escolar. 
Os apontamentos das docentes investigadas evidenciam uma escola desprovida de um mínimo de recursos estruturais para executar uma aula de qualidade. Computadores sucateados, internet que não funciona, biblioteca desatualizada, folhas de ofício contadas, classes e cadeiras quebradas, bem como o desprestígio do ser docente, são alguns dos limitadores que acabam influenciando na atual conjuntura de fragilidades em que a escola brasileira se encontra.

Vivemos num tempo de rápidas mudanças e de crises nos relacionamentos humanos. Agir diante da violência na escola é tomar consciência de que a educação brasileira é tarefa de todos e que o professor, enquanto agente do processo educativo, precisa ser respeitado enquanto profissional da educação, pois é peça fundamental na formação de uma sociedade mais humana, mais ética, mais cidadã.

Por fim, as reflexões apresentadas sinalizam para a necessidade de futuros estudos e reforçam o pensamento de que para educar um aluno é preciso toda uma cidade. $E_{1}$ é no aprender a desafiar-se cotidianamente através de uma pedagogia do afeto, do diálogo e do comprometimento com a vida que os educadores irão provocar a abertura de novas veredas.

\section{Referências}

ABRAMOVAY, M. (Org.). Escola e violência. Brasilia: UNESCO, 2002a.

ABRAMOVAY, M.; RUA, M. G. Violência nas escolas. Brasilia, DF: UNESCO, $2002 b$.

BARBOSA, L. M. S. PCNs: Parâmetros Curriculares Nacionais: temas transversais: uma interpretação e sugestões para a prática. Curitiba: Bella Escola, 2002. v. 2.

BARROS, C. S. G. Pontos de psicologia do desenvolvimento. 10. ed. São Paulo: Ática, 1997.

BAUMAN, Z. Amor líquido: sobre a fragilidade dos laços humanos. Rio de Janeiro: Jorge Zahar, 2004.

. Modernidade líquida. Rio de Janeiro: Jorge Zahar, 2001.

. O mal estar da pós-modernidade. Rio de Janeiro: Jorge Zahar, 1998.

BEAUNDOIN, M. N.; TAYLOR, M. Bullying e desrespeito: como acabar com esta cultura na escola. Porto Alegre: Artmed, 2006. 
BOGDAN, R. C.; BIKLEN, S. K. Investigação qualitativa em educação: uma introdução à teoria e aos métodos. Porto: Porto, 2003.

BRASIL. Lei n 8.069, de 13 de julho de 1990. Dispõe sobre o Estatuto da Criança e do Adolescente e dá outras providências. Diário Oficial [da] República Federativa do Brasil], Brasília, DF, 16 jul. 1990.

. Lei n$^{\circ}$ 9.394, de 20 de dezembro de 1996. Estabelece as Diretrizes e Bases da Educação Nacional. Diário Oficial [da] República Federativa do Brasil], Brasília, DF, 23 dez. 1990.

BULLYNG. Wikipédia, 2010. Disponivel em: <http://pt.wikipedia.org/wiki/ Bullying >. Acesso em: 8 jul. 2010.

CHARLOT, B. A violência na escola: como os sociólogos franceses abordam essa questão. Sociologias. Porto Alegre, v. 4, n. 8, p. 432-443, jul./dez. 2002.

CONSELHO NACIONAL DE EDUCAÇÃO (Brasil). Parecer CNE/CEB nº 4, de 29 de janeiro de 1998. Diretrizes Curriculares Nacionais para o Ensino Fundamental. Brasilia, DF, 1998. Disponivel em : < www.crmariocovas.sp.gov.br/pdf/.../ 06_parecer_cne-ceb_04-98.pdf>. Acesso em: 1 jul. 2010.

CUBERO, R.; MORENO, M. C. Relações sociais nos anos escolares: família, escola, companheiros. In: COLL, C.; PALACIOS, J. Desenvolvimento psicológico e educação. Porto Alegre: Artmed, 1995.

DELORS, J. (Org.). Educação: um tesouro a descobrir. 8. ed. São Paulo: Cortez; Brasilia, DF: MEC: UNESCO, 2003.

GIMENO SACRISTÁN, J. A educação que temos, a educação que queremos. In: IMBERNÓN, F. (Org.). A educação no século XXI: os desafios do futuro imediato. 2. ed. Porto Alegre: Artmed, 2000.

IMBERNÓN, F. (Org.). A educação no século XXI: os desafios do futuro imediato. 2. ed. Porto Alegre: Artmed, 2000.

Formação docente: formar-se para a mudança e a incerteza. 5. ed. São Paulo: Cortez, 2005.

KONZEN, A. A. Pertinência socioeducativa: reflexões sobre a natureza jurídica das medidas. Porto Alegre: Livraria do Advogado, 2005. 
LIBÂNEO, J. C.; OLIVEIRA, J. F.; TOSCHI, M. S. Educação escolar: políticas, estrutura e organização. São Paulo: Cortez, 2003.

MASETTO, M. T. Didática: a aula como centro. São Paulo: FTD, 1997.

NASCIMENTO, M. G. C. A. Violência na escola: o que pensam os (as) professores (as). Século XXI, Rio de Janeiro, nov. 2006. Seção Sociedade Enclausulada. Disponivel em: $<$ http://www.multirio.rj.gov.br/seculo21/texto_link.asp?cod_link= 118ctcod_chave $=2$ ttletra $=\mathrm{h}>$. Acesso em: 7 nov. 2006 .

NÓVOA, A. Professor se forma na escola. Nova Escola. São Paulo, n. 142, abr./ maio 2001.

SCHILLING, F. A sociedade da insegurança e a violência na escola. São Paulo: Moderna, 2004.

TUVILLA RAYO, J. Educação em direitos humanos: rumo a uma perspectiva global. Porto Alegre: Artmed, 2004.

VASCONCELLOS, C. S. Para onde vai o professor?: resgate do professor como sujeito de transformação. 8. ed. São Paulo: Libertad, 2001.

VEIGA, I. P. A (Org.). Projeto político-pedagógico: uma construção possível. 12. ed. São Paulo: Papirus, 2001.

Recebido em: 12/02/2009

Aceito para publicação em: 20/07/2009 